Review Article

\title{
Short stature among girl child: a psychological burden or a social stigma-a review
}

\author{
Karishma Sharma ${ }^{1}$, Brijendra Singh', Manisha Naithani ${ }^{2}$, \\ Rishita Chandra ${ }^{3}$, Prashant K. Verma ${ }^{4 *}$
}

\begin{abstract}
${ }^{1}$ Department of Anatomy, ${ }^{2}$ Department of Biochemistry, ${ }^{3}$ Department of Community and Family Medicine, ${ }^{4}$ Department of Pediatrics, AIIMS, Rishikesh, Uttarakhand, India
\end{abstract}

Received: 18 March 2021

Accepted: 15 April 2021

\section{*Correspondence:}

Dr. Prashant K. Verma,

E-mail: 2004pkv@gmail.com

Copyright: ( ) the author(s), publisher and licensee Medip Academy. This is an open-access article distributed under the terms of the Creative Commons Attribution Non-Commercial License, which permits unrestricted non-commercial use, distribution, and reproduction in any medium, provided the original work is properly cited.

\begin{abstract}
Short stature (SS) is defined as "height below the third percentile or less than two standard deviations below the median height for that age and sex according to the population standard". Short stature is not itself a pathology or disease but sometimes may be present as a manifestation of some underlying pathological condition. This condition is seen to impact adversely on the psychological wellbeing of the affected individuals and gives rise to the social stigma which further worsens the quality of life of short-statured persons. Hence, there is a need to acknowledge and break this stigma thereby improving the psychological wellbeing of the short-statured population.
\end{abstract}

Keywords: Short stature, Social stigma, Bullying, Self-esteem

\section{INTRODUCTION}

The term stature represents the vertical height. It is defined as the height of a person taken from the bottom to the vertex when the head is held in the Frankfurt horizontal plane (F-H plane). An investigator can use any of the different devices for estimating the height of a person, for example, stadiometer, infantometer, measuring tape, and anthropometric rod. ${ }^{1}$

Optimum growth and development in a child is directly with a child's health and nutrition. Therefore, in pediatric care, growth assessment is of utmost importance. Adequate growth suggests good health and nutrition. In contrast, short stature can indicate some underlying issues or pathology related to the child's physiological functions and genetics or nutritional status. A number of factors can be traced for short stature, namely, prenatal and postnatal conditions, genetics, endocrine disorders, extrinsic factors like environment, etc. The etiology can be relatively significant in different populations. ${ }^{2}$ The diagnosis of short stature requires biochemical and radiological investigations, including nutritional and hormonal assessment and estimation of bone age.

\section{SHORT STATURE: DEFINITION AND ASSOCIATED FACTORS}

Short stature (SS) is defined as "height below the third percentile or less than two standard deviations below the median height for that age and sex according to the population standard." Short stature is not itself a pathology or disease but is presented as a manifestation of some underlying pathological conditions. The children having short stature undergo a variety of psychological stresses and emotional trauma in addition to the conditions that cause short height in them. ${ }^{3}$

There are many factors that contribute to short stature; for example, SS may result from endocrine disorders, skeletal dysplasia, or genetic or familial predisposition. It can ensue as a result of malnutrition and some other chronic 
illnesses. A study conducted in Mumbai, India by Colaco et al found out $5.6 \%$ of short stature in study participants. ${ }^{4}$

According to Ranke, "short stature is defined as a condition in which the height of an individual is two standard deviations (SD) below the corresponding mean height of a given age, sex and population group." In medical terminology, it is known as "dwarfism."5

When we discuss the types of short stature, two types are prevalent i.e. proportionate short stature (PSS) and disproportionate short stature (DSS). When the person presents with usual proportion in the height of limbs and trunk, it is called as proportionate short stature, while in the absence of this usual proportion, the person can reflect a remarkable difference in standing and sitting height, and the condition is called as disproportionate short stature.

The primary management of short stature aims to alleviate the underlying cause and treat the associated psychosocial distress.

\section{PSYCHOLOGY OF THE SHORT-STATURED GIRLS}

As per the available literature on sociology, many stigmatizing factors have been discussed and have been brought to the mainstream research. Though the literature is not rich in the information related to stigma with short height even though height is a standard and visible representation and part of one's daily life, it does reveal various anecdotes that talk about the individuals' psychology with short stature and present to the pediatric clinics. $^{6}$

Short-statured individuals' experiences suggest about the overall episodes of teasing, bullying, and comments estimating their intelligence as per their height. They face hard time socializing as society assesses them according to their height, age, and chronological age. This forced juvenilization affects their self-esteem and also sometimes academic achievement.

A community-based study conducted by Downie et al in the United Kingdom showed that only $12 \%$ of healthy child but with visible impairment in the growth i.e. short stature were satisfied with their height. The rest of the study participants reflected disappointment with their height. ${ }^{7}$

As per the sociological standards, various studies have explored this domain and concluded that height serves as an axis of difference that can determine the dominance and discrimination. Moreover, the available talks are more about men's issues, and the impact of this psychosocial phenomenon among girls regarding their body image often remain under-reported or underestimated. It might reflect falsely that females remain unaffected by this stigma. Hence, there is a need to bridge this gap by quoting incidents and anecdotes where a girl child felt emotionally traumatized and went beyond her way to mark her presence and importance within their family, including a compulsive behavior of attention-seeking which instills a negative attitude in them. ${ }^{8}$

Short stature can appear as an isolated physical trait in an otherwise normal and healthy child, which we call "idiopathic short stature". Amongst others, the major concern here is that these children are considered disproportionate. ${ }^{9}$ In a survey conducted by Cuttler et al, $56 \%$ of the physicians were of the opinion that impaired height has a significant impact on the emotional and mental well-being of the child. ${ }^{9}$

When a child or an adolescent is treated according to his/her height age instead of the chronological age, they tend to develop a negative feeling towards socializing and become introverts may even turn anti-social. They may also withdraw themselves from their peer group and start spending time with younger group of children to fit in. They can also be comfortable with the older age group as there are negligible chances of comparison. ${ }^{10}$

In 1994, Sandberg reported 522 consecutive referrals for short stature to the pediatrician. They included selfreporting cases as well as those brought in by parents. The majority of the individuals have experienced episodes of teasing and bullying. They have reported undergoing juvenilization for being a short-statured child. This has presented some difficulties in their behavioral adaptation. ${ }^{11}$

\section{THE PSYCHOSOCIAL DIMENSION OF THE STIGMA RELATED TO THE SHORT STATURE OF GIRLS}

As discussed above, the concerns and issues related to the social adaptation have included unassertiveness, juvenilization, immaturity and stigmatization. When it comes to the female gender, being a short-statured woman puts them in a precarious position in the community and society as a whole.

Goffmann has worked on stigma, and in his work, he has discussed the differences in the characteristics that are visible and invisible in someone's personality. He states that "visibility, of course, is a crucial factor. That which can be told about an individual's social identity at all times. The consequence of a presentation or a performance made to the public at large may be small in particular contacts, but in every contact, there will be some consequences, which when taken together, can be immense in effect." 12 Height is a visible identity, which can't be changed beyond measures and hence affects the individual's social interaction.

Link and Phelan have also conceptualized the association between stigma and the visible identity of an individual, height being the one that affects it. They state, "stigma exists when elements of labeling, stereotyping, separation, status loss, and discrimination occur together in a power 
situation that allows them." 13 This statement reveals that the social process of stigmatizing is governed by a combination of complex factors having synergistic effects to the height.

\begin{abstract}
"Although psychologists have long been interested in the causes of stereotyping, prejudice, and discrimination, only recently have they focused in earnest on understanding the psychological effects of these processes." ${ }^{14}$ In the case of short women, the coping model for the stress needs to be instructive enough. There is a need that they should be guided sufficient to combat this psychosocial issue related to short stature without demeaning their identity. With variation in the degree of stigma is reported according to the individuals. The degree of emotional threat and psychological trauma differs from individual to individual.
\end{abstract}

\section{Short stature and parent's attitude}

Law states that "in short children, age tends to be underestimated, and this can lead to the child being infantilized by parents, peers, and teachers". He suggests that infantilization is one of the most prominent factors affecting short women, even when they grow as adults. When they are fully grown chronologically still lack in their height, they often lose their self-esteem and confidence. The preconceived notion that society will equate their age with height is challenging for the adults and puts extra pressure on their minds. Growing up as an adult put additional strain on their minds and might become the reason for various insecurities. ${ }^{15}$

The attitude of parents matters the most in the conditioning of a child. Their ill-behavior or society-driven attitude can cause trauma to their child and impact their mood and the kind of individual they will grow into. Hence, if parents carry on positive reinforcement, it can enhance their selfesteem and courage to face society.

\section{Short-stature and mindset}

Many women find it challenging to make eye contact while having a conversation due to their short-height. They find themselves getting overlooked, "because you're not really on normal people's eye level. So it's harder to make eye contact in conversations." Many women feels that they get more attention from people at her actual height than she does when she puts on heels. Several other participants also mentioned that "they felt their height garnered them more attention, which was not always positive". ${ }^{16}$ Obviously, they wanted to be recognized for other traits and qualities rather than just height as an identity is much more than the visible appearance. They felt that the norm of getting validated and objectified based on a few more feet or inches is derogatory to a woman's personality.

\section{Short stature and job profile}

Several job profiles have always been considered suitable for taller individuals, e.g. modeling and glamour world, sports like basketball. But people with firm determination and vision have overcome this stigma and not only established a successful career but got famous with their self-identity. Quoting the example of celebrities, the popicon Lady Gaga being only 5'1', height, has flourished in her career, and irrespective of people's perception, she carries herself with confidence. A basketball celebrity, NBA legend Muggsy Bogues' has been considered the shortest player and still claimed to fame. The god of cricket, Sachin Tendulkar, has unfurled so many flags of victory and proved that height need not be stigmatized; rather dreams should be materialized through consistent efforts and high self-esteem. However, many professions still have a benchmark height especially in hospitality services which do not consider people under a certain height.

A positive mindset needs to start with accepting oneself the way they are. People with short-stature should focus on their emotions and deal with their vulnerabilities. A little family and friends' support can help them become emotionally intelligent and stop seeking external validation. We believe that as a society we must become inclusive to let go of our discriminations. Measures and incremental efforts to enhance social identification can go a long way and enrich lives of everyone as a part of society.

\section{CONCLUSION}

The short stature phenomenon though being related to health and appearing as a manifestation of some underlying physiological disorder or familial predisposition, is a psychological concern. The sociology aspect needs to deal with this phenomenon of stigmatizing and juvenilizing the women with short height affirmatively. The identity of a woman shall not be objectified on the basis of how many feet or inches she is smaller than the normal. The emotional trauma and stress a girl child undergoes might instill insecurities, and she might grow as an under-confident adult and start to dislike herself eventually preventing her full potential to self and society.

Hence, the gap between the girls' psychology with short stature and the familial and societal perception needs to be filled with behavior changes in the families, in the community and as society.

Funding: No funding sources Conflict of interest: None declared Ethical approval: Not required

\section{REFERENCES}

1. Warrier V, Krishan K, Shedge R, Kanchan T. Height Assessment. 2020 May 5. In: StatPearls. Treasure Island (FL): StatPearls Publishing. 2021.

2. Bhadada SK, Agrawal NK, Singh SK, Agrawal JK. Etiological profile of short stature. Indian J Pediatr. 2003;70:545-7. 
3. Zlotkin D, Varma SK. Psychosocial effects of short stature. Indian J Pediatr. 2006;73:79-80.

4. Colaco P, Desai M, Choksi CS. Short stature in Indian children: the extent of the problem. Indian J Pediatr. 1991;1:57-8.

5. Rani D, Shrestha R, Kanchan T, et al. Short Stature. In: StatPearls. Treasure Island (FL): StatPearls Publishing. 2021.

6. Conrad P, Potter D. Human growth hormone and the temptations of biomedical enhancement. Sociol Health Illness. 2004;26(2):184215.

7. Busschbach JJ, Rikken B, Grobbee DE, De Charro FT, Wit JM 1998 Quality of life in short adults. Horm Res. 49:32-8.

8. Boulton TJC, Dunn SM, Quigley CA, Taylor JJ, Thompson L, Members of the Australasian Paediatric Endocrine Group. Perceptions of self and short stature: Effects of two years of growth hormone treatment. Acta Paediatr Scan Suppl. 1991;377:2027.

9. Cuttler L, Silvers JB, Singh J, Marrero U, Finkelstein B, Tannin G, Neuhauser D. Short stature and growth hormone therapy. A national study of physician recommended patterns. J Am Med Assoc. 1996;276:531-7.

10. Meyer-Bahlburg HFL. Short stature: psychological issues. In Pediatric Endocrinology. A Clinical Guide, 2nd edn. Ed. F Lifshitz, New York: Marcel Dekker, 1990;173-96.

11. Sandberg DE, Brook AE, Campos SP. Short stature: a psychosocial burden requiring growth hormone therapy? Pediatrics. 1994;94:832-40.
12. Goffman E. Stigma: Notes on the Management of Spoiled Identity. New York: Simon and Schuster. 1963.

13. Link BG, Phelan JC. Conceptualizing stigma. Ann Rev Sociol. 2001;27(2001):363385.

14. Major B, O'Brien LT. The social psychology of stigma. Ann Rev Psychol. 2005;56:93421.

15. Law CM. The disability of short stature. Arch Dis Childhood. 1987;62(8):855859.

16. Scott J, Marshall G. Master status. A dictionary of sociology. 2009. Available at: http://www.oxfordre ference.com.proxy.lib.umich.edu/view/10.1093/acre f/9780199533 008.001.0001/acref-9780199533008. Accessed on 24 January 2021.

17. Jetten J, Branscombe NR, Schmitt MT, Spears R. Rebels with a cause: Group identification as a response to perceived discrimination from the mainstream. Personality Social Psychol Bull. 2001;27:12041213.

Cite this article as: Sharma K, Singh B, Naithani M, Chandra R, Verma PK. Short stature among girl child: a psychological burden or a social stigma-a review. Int J Community Med Public Health 2021;8:2588-91. 